\title{
Sensitivity and Variability of Maximum Trunk Shrinkage, Midday Stem Water Potential, and Transpiration Rate in Response to Withholding Irrigation from Field-grown Apple Trees
}

\author{
A. Naor \\ Golan Research Institute, P.O. Box 97, Kazrin 12900, Israel

\section{S. Cohen} \\ Department of Environmental Physics and Irrigation, Institute of Soils and \\ Water, P.O. Box 6, Bet Dagan 50250, Israel
}

Additional index words. water stress indicators, irrigation scheduling, Malus $\times$ domestica

\begin{abstract}
The sensitivity of water stress indicators to changing moisture availability, and their variability, determine the number of measurements that should be taken in order to represent properly plant water status in a certain orchard. In the present study we examined the sensitivity and variability of maximum daily trunk shrinkage, midday stem water potential, and daily transpiration rate in their responses to withholding irrigation from field-grown drip-irrigated 'Golden delicious' apple trees in a commercial orchard. Irrigation was withheld from the stressed trees for 17 days starting in mid-July, and the control trees were irrigated daily at $100 \%$ of the "Class A" pan evaporation rate. The courses of daily transpiration rate, maximum trunk shrinkage, and midday stem water potential before and $\mathbf{1 0}$ days after the drying period were similar in the control and the stressed trees. Highly significant differences between the stressed and the control trees in their midday stem water potentials were apparent from the early stages of the stress period. Daily transpiration rate and maximum daily shrinkage were more variable than midday stem water potential, and differences between treatments became significant only after measurements were expressed relative to the initial values before irrigation was witheld. Differences between treatments (as percentages of the values obtained for the control trees) increased after irrigation stopped where these differences were greatest for maximum daily shrinkage, which reached $90 \%$; moderate for stem water potential $(60 \%)$; and least for daily transpiration rate, for which the differences remained below $20 \%$. Our data show that the choice of a certain water stress indicator should be based on both the sensitivity to changing moisture availability and the degree of variability. Possible reasons for the different sensitivity to moisture availability and the different variability between the water stress indicators under study are discussed.
\end{abstract}

Worldwide the amount of fresh water available for irrigation is decreasing, and the decrease is greater in semi-arid zones, where drinking water resources are limited. Therefore, there is a constant need to improve water use efficiency, and accurate irrigation scheduling is one of the major tools that growers can utilize to achieve this goal. Irrigation scheduling has been studied in detail for decades, and significant progress has been achieved over the years in the understanding of water transport through the soil-plant-atmosphere continuum (Itier and Brunet, 1996). However, it is still impossible to obtain accurate predictions of the crop water requirement for field conditions in perennial fruit tree orchards. In modern irrigation sched-

Received for publication 27 July 2001. Accepted for publication 10 Nov. 2002. We are grateful to A. Wallach, A. Grava, Yefet Cohen, Yen Li, and Fusheng Li for technical assistance; and to Kibbutz Ortal for hosting the experiment. uling, the basic irrigation rate is calculated by multiplying the daily evapotranspiration of a reference crop, or the daily evaporation from a standard pan, by a specific crop coefficient (Howell, 1996). The calculated irrigation rate should be corrected for actual canopy size (Johnson et al., 2000), actual crop load (Naor et al., 2001), and site-specific irrigation efficiency, i.e., the proportion of the irrigation water that remains in the rooting zone, which is not easy to determine. The adjustment of the crop coefficient is being done by the aid of soil and/or plant water status.

Soil water status sensors are the most popular water stress indicators for irrigation scheduling (Howell, 1996; Phene et al., 1990), including in perennial trees. In general, they are easy to use and most of them provide analog outputs that allow continuous monitoring. The root zone of perennial trees is irregular and usually occupies a large non-uniform soil volume, which exceeds the irrigated volume; therefore, the choice of locations in which to monitor the soil water status is problematic.
In addition, the soil water content is spatially variable within an orchard; therefore, one would need dozens of measurements in order to represent the soil water status properly (e.g., Russo and Bresler, 1982; Warrick and Nielsen, 1980). The problems of transforming these measurements into an estimate of soil water availability and of setting a threshold for irrigation scheduling would still remain unsolved. In spite of the above limitations, growers make wide use of soil water status sensors, and set their own irrigation scheduling thresholds empirically.

Plant water status indicators have been used mainly in research on environmental physiology and irrigation, and their practical application for irrigation scheduling has been limited. Predawn and midday leaf water potentials have been the most popular plant water status parameters proposed for irrigation scheduling in orchards. Research in the past decade suggests that midday stem water potential is a significant and reliable plant water status indicator for scheduling the irrigation of many fruit trees (Naor, 1999; Shackel et al., 1997); these include almond (Gurusinghe and Shackel, 1995), apple (Naor et al., 1995; 1997), nectarine (Naor et al., 1999, 2001), pear (Marsal et al., 2002; Naor et al., 2000; Ramos et al., 1994), prune (Lampinen et al., 1995; McCutchaan and Shackel, 1992; Shackel et al., 2000), grapevines (Chone et al., 2001), and litchi (Stern et al., 1998). The main disadvantage of midday stem water potential is the relatively cumbersome measurement procedure. Dixon and Tyree (1984) developed a plant dewpoint hygrometer that reduces measurement errors by minimizing temperature gradients and allows a continuous reading of trunk water potential, but to date none are commercially available for field tests.

Diurnal stem diameter contraction was proposed in the past (Klepper, 1968; Klepper et al., 1971) as an indicator of plant water status and it has been shown to be indirectly related to leaf water potential (Molz and Klepper, 1973). The use of measurements of diurnal changes in stem diameter for irrigation scheduling has attracted renewed attention because of improvements in LVDT robustness (Cohen et al, 2001; Goldhamer et al., 1999a, 1999b; Huguet et al., 1992), and maximum daily trunk shrinkage (MDS) was proposed as a plant water stress indicator for irrigation scheduling because it was found highly responsive (sensitive) to changing soil moisture availability (Cohen et al., 2001; Goldhamer et al., 1999a, 1999b).

Sensitivity to changing moisture availability should be a predominant factor in the choice of a water stress indicator. However, variability should also be taken into account, as both sensitivity and variability will determine how many measurements are needed to represent properly the plant water status in a certain orchard. The objective of the present project was to compare both the sensitivity and the variability of maximum daily trunk shrinkage, midday stem water potential, and tree transpiration rate in response to a cycle of withholding and resuming irrigation of apple trees. 


\section{Materials and Methods}

Climatic conditions. The experimental site was located in the Golan Heights, Israel $\left(33^{\circ} \mathrm{N}, 36^{\circ} \mathrm{E}\right), 1000 \mathrm{~m}$ above mean sea level, where there is a semi-arid climate with rainless summers. Average precipitation (October-April) is $\approx 800 \mathrm{~mm}$. Average maximum daily temperature and vapor pressure deficit in the experimental plot during July and Aug. 1999 were $27.9{ }^{\circ} \mathrm{C}$ and $1.9 \mathrm{kPa}$, respectively.

Experimental plot. The experimental plot consisted of a 13-year-old drip-irrigated commercial orchard of 'Golden Delicious' apple (Malus $\times$ domestica Borkh.) grafted on local (Hashabi) rootstock, with $2 \times 4 \mathrm{~m}$ spacing. Tree height was about $3.5 \mathrm{~m}$ and the rows were planted in a north-south orientation. The irrigation system consisted of one lateral line per row with $3.5-\mathrm{L} \cdot \mathrm{h}^{-1}$ pressure-compensated inline drippers spaced $0.70 \mathrm{~m}$ apart. The experimental plot was irrigated daily during the course of the experiment.

Treatments. The control treatment was irrigated at $100 \%$ of the "Class A" pan evaporation rate throughout the course of the experiment. Irrigation in the stressed treatment was the same as for the control treatment until 20 July 1999 , after which irrigation was withheld for $17 \mathrm{~d}$. Irrigation was then resumed at $150 \%$ of the pan evaporation rate for $3 \mathrm{~d}$ to recharge the soil profile, followed by irrigation at $100 \%$ of pan evaporation thereafter.

Trunk radius measurements. The radius of the tree trunk was measured continuously with electronic (LVDT) dendrometers (DF/ 2.5, Solartron, U.K.). One dendrometer was installed on each tree, $20-40 \mathrm{~cm}$ aboveground, below the first branch. The dendrometers were connected to a CR10 data logger (Campbell Scientific, Logan, Utah). Measurements were taken every $5 \mathrm{~s}$, and the average was recorded every $10 \mathrm{~min}$. The maximum daily shrinkage (MDS) was calculated by subtracting the minimum (afternoon readings) from the maximum (morning readings) radius.

Transpiration rate measurements. Transpiration rate was measured by the heat pulse technique according to Cohen et al. (1981), with sap flow sensors and an apparatus made in our laboratory. With this technique, sap flow is measured simultaneously at six depths in the xylem by monitoring the time taken for a short heat pulse to move $15 \mathrm{~mm}$ in the trunk. Heat pulse probes were installed in each tree, 20-40 cm aboveground, below the first branch, and measurements were taken every hour. Parameters for wood properties were taken from Jones et al. (1988).

Stem water potential measurements. Midday stem water potential was measured several times during the course of the experiment. Two leaves per tree were selected from the inner part of the canopy, close to the trunk; they were enclosed, while still attached, in "Zip-Loc" plastic bags covered with aluminum foil. The leaves remained covered in the bags for at least 90 min to allow equilibration with the stem water potential; they were then detached and their water potential was measured in a pres-

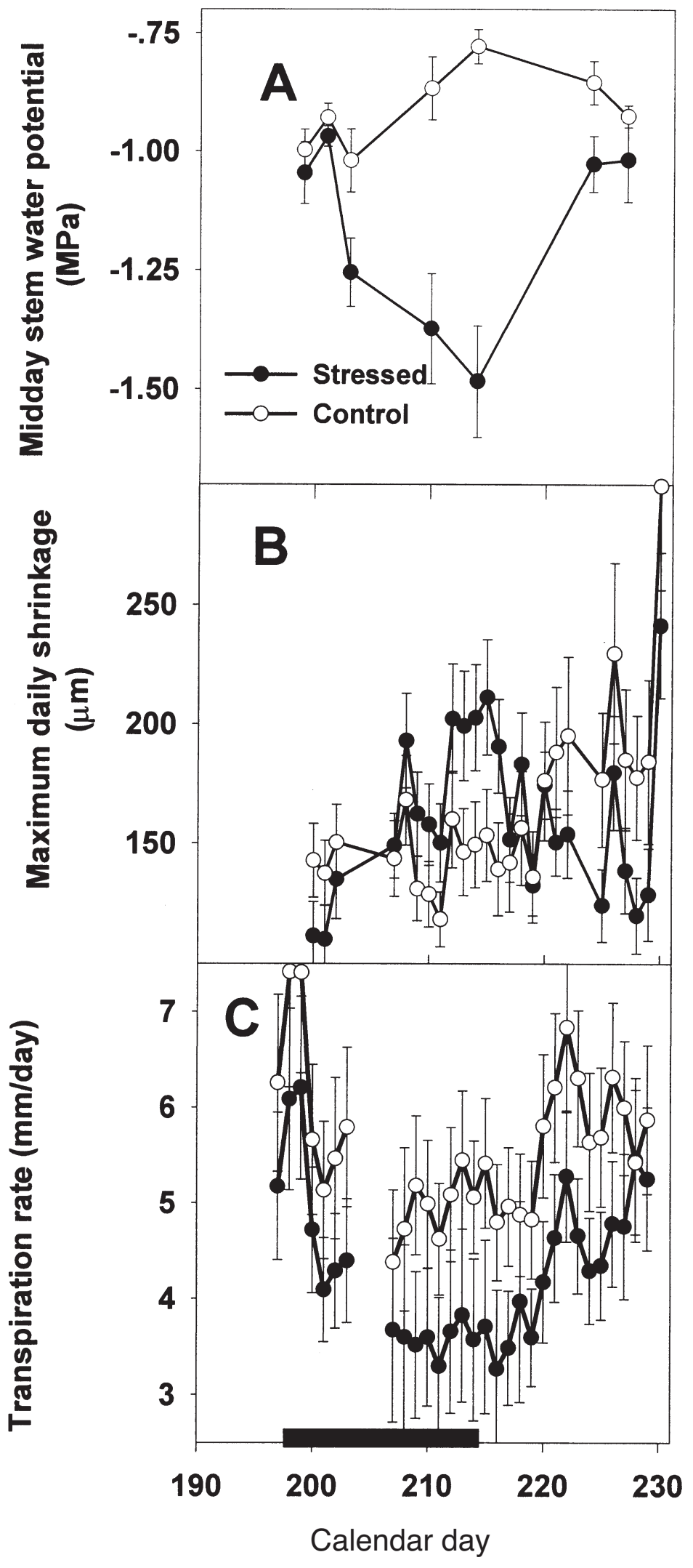

Fig. 1. (A) Midday stem water potential, (B) maximum daily trunk shrinkage, and (C) daily transpiration rate of the control and stressed apple trees during a cycle of withholding and resumption of irrigation. The bold horizontal bar indicates the dates when water was withheld from the stressed trees. Vertical bars indicate standard error. 
sure chamber (Ari-Mad, Kfar Charuv, Israel) (Scholander et al., 1965).

Statistical design and analysis. The experiment was conducted on three adjacent rows. Each experimental plot consisted of three rows, each with four trees. Measurements were taken in the two inner trees of the central row of each experimental plot; the other trees served as border trees. The treatments were replicated three times along the three rows, in a complete randomized block design. MDS, daily transpiration rates, and midday stem water potential values for each day in each plot (i.e., two trees) were averaged before the mean and standard errors of each treatment were calculated.

\section{Results}

The midday stem water potentials of the control treatment ranged from -0.8 to -1.0 MPa throughout the course of the experiment, and similar midday stem water potentials were observed in the trees designated for stressing before irrigation was withheld (Fig. 1A). The midday stem water potential of the stressed trees decreased after irrigation was stopped, and reached a minimum of $-1.5 \mathrm{MPa}$. Ten days after the resumption of irrigation, the midday stem water potential of the stressed trees recovered to the same level as that in the control trees. Differences between the two irrigation treatments were highly significant from the early stages of the drying period (Fig. 1A). The midday stem water potential of the stressed treatment was more variable (i.e., it exhibited a larger variance) than that of the control treatment The MDS of the stressed trees increased after irrigation was stopped and decreased after it was resumed (Fig. 1B). The daily transpiration rate of the stressed trees was $\approx 6 \mathrm{~mm}$ before irrigation was stopped and decreased to $3.5 \mathrm{~mm}$ during the drying period (Fig. 1C). However, transpiration rate was highly variable in both the control and the stressed treatments (Fig 1C) and the differences between the treatments were nonsignificant, even at the end of the drying period.

The higher variability of the MDS (Fig. 1B) and daily transpiration (Fig. 1C) vs. that of midday stem water potential is related in part to their higher initial variability before irrigation was withheld (Fig. 1A). In order to eliminate the initial variability, each MDS and daily transpiration value was expressed relative to its initial value before irrigation was withheld. The MDS of each tree relative to its initial value was much less variable (Fig 2A) than its absolute value (Fig. 1B), and the differences between treatments, in relative values, were significant (Fig. 2A). Similarly, the daily transpiration in each tree relative to its initial value was much less variable (Fig. 2B) than its absolute value (Fig. 1C), and the differences between the two irrigation treatments, in relative values, were significant (Fig. 2B). The MDS and daily transpiration rate of the stressed treatment were more variable than those of the control treatment (Fig. 2A-B).

The dimensions of the three water stress indicators under study are different, $\mathrm{MPa}, \mu \mathrm{m}$, and $\mathrm{mm} \cdot \mathrm{day}^{-1}$, for the stem water potential,

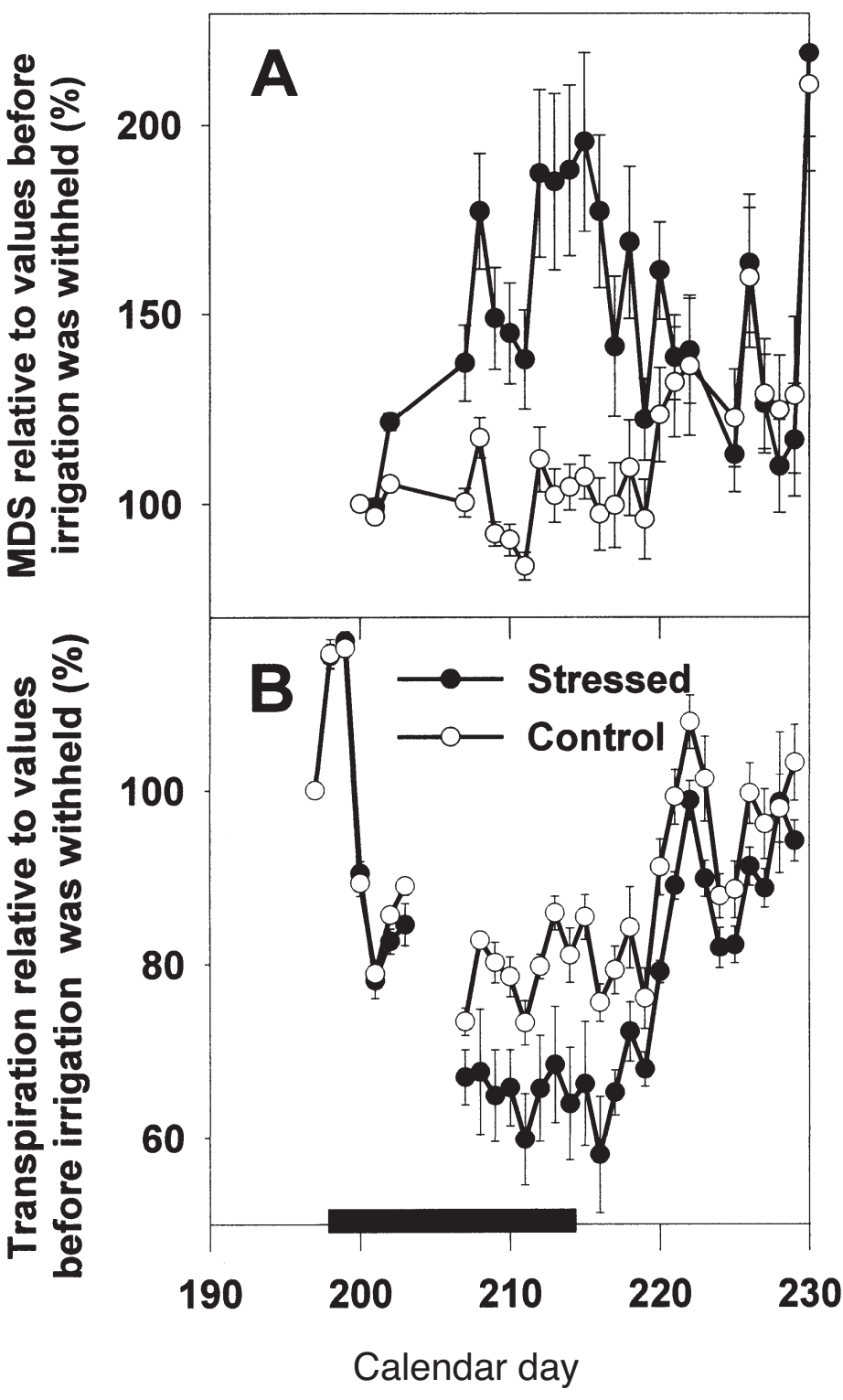

Fig. 2. Maximum daily trunk shrinkage (A) and daily transpiration rate (B), relative to the initial values in each tree $(\%)$ in the stressed and the control apple trees, during a cycle of withholding and resumption of irrigation. The bold horizontal bar indicates the dates when water was withheld from the stressed trees. Vertical bars indicate standard error.

MDS and daily transpiration, respectively; therefore, the comparison of the absolute values of these water stress indicators is meaningless. In order to allow a meaningfull comparison of the sensitivity of the three water stress indicators, the differences between the stressed trees and the control trees were expressed relative to the readings of the control trees (Fig. 3). Differences between treatments (as percentages of the control tree values) increased after irrigation stopped (Fig. 3). These differences were greatest for MDS, for which they reached $90 \%$; moderate for midday stem water potential $(60 \%)$; and least for daily transpiration rate, for which the differences did not exceed $20 \%$.

\section{Discussion}

Sensitivity of the measured parameters to changing moisture availability. Both MDS and midday stem water potential were more responsive to changes in soil moisture availability than the daily transpiration rate (Fig. 3 ). MDS and midday stem water potential are indicators of the maximum daily plant water stress, whereas the daily transpiration rate is integrated through the day. Therefore, it seems that integrative indicators, such as daily transpiration, are less sensitive to soil moisture availability because they respond to the average water stress during the day and not to the maximum daily water stress. Consequently, integrative water stress indicators might not be good enough for irrigation scheduling.

It is well established that the main factor controlling MDS is leaf water potential (Molz and Klepper, 1973), which determines the driving force for water transport between the bark and the xylem vessels. Therefore, the sensitivity of stem water potential to changes in moisture availability was expected to be at least similar to that of MDS. However, the MDS 


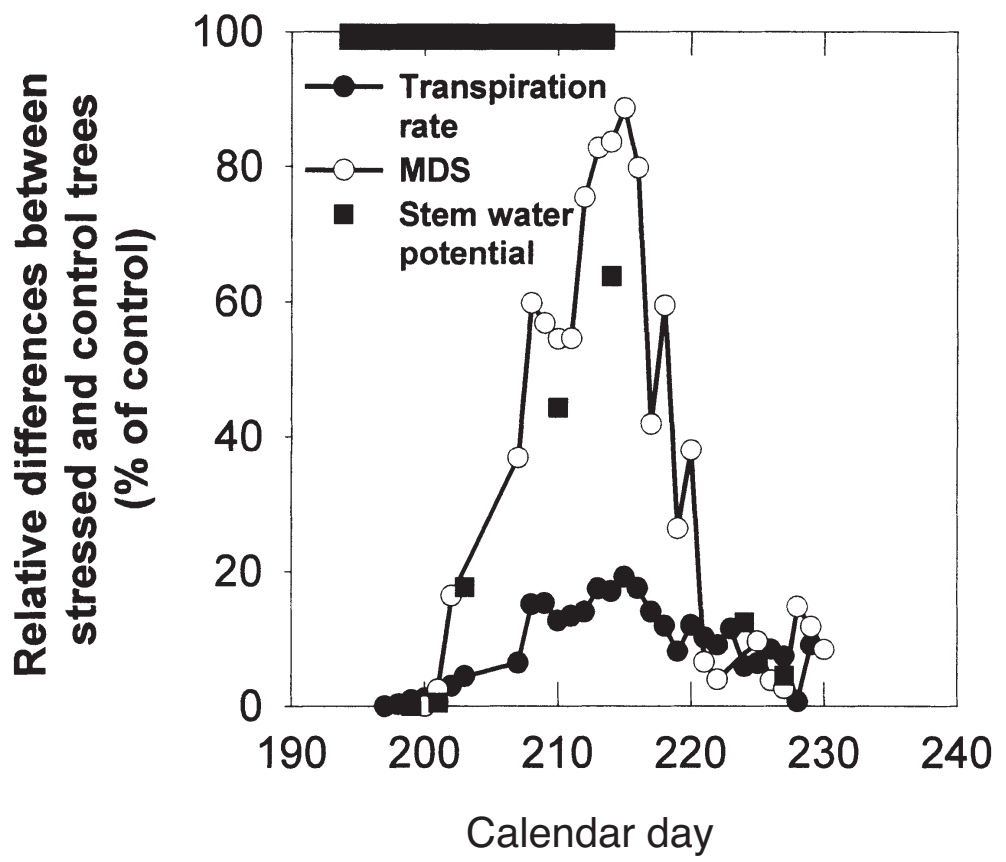

Fig. 3. Differences between the stressed and the control apple trees (\% of control trees) during a cycle of withholding and resumption of irrigation. The bold horizontal bar indicates the dates when water was withheld from the stressed trees.

was found to be more responsive to changes in soil moisture availability than the midday stem water potential, both in the present study (Fig. 3) and in previous investigations (Cohen et al., 2001; Fereres et al., 1999; Goldhamer et al., 1999a, 1999b). This could result from non-linearity of the relationship between the stem water potential and the trunk diameter (water retention curve).

Variability and water stress. All measured parameters had higher variances in stressed than in control trees (Figs. 1A, 2A-B), a phenomenon that has been reported previously for fruit trees, e.g., apple (Naor et al., 1995) and litchi (Stern et al., 1998). Based on this phenomenon, it has been suggested that variability in itself might serve as a water stress indicator (Aston and van Bavel, 1972; Fuchs, 1990), but it did not reach the stage of practical application. The higher variability of the stressed treatment is due to the increase in the variability of soil moisture on the field scale, when soil moisture decreases (Russo et al., 1994). Variability in plant water stress indicators becomes more pronounced when soil moisture becomes a limiting factor.

Variability of the measured parameters. MDS and daily transpiration rates were much more variable than the midday stem water potential (Fig. 1). The similar stem water potential in the two treatments prior to withholding irrigation, indicates that the selected trees for the experiment were quite uniform; it may also suggest that the initial differences in MDS and daily transpiration rate, and the high variance in those water stress indicators is related solely to the measurement techniques. The variability of both MDS and daily transpiration decreased dramatically when the data were expressed relative to their initial values prior to withholding irrigation (Fig. 2A-B); this revealed their sensitivity to soil moisture changes, and the differences between treatments became significant. However, such data manipulation cannot be applied in a practical irrigation scheduling process because the reference (non-stressed) conditions do not always exist.

Variability in transpiration rates could result from differences among the measured trees in their canopy sizes, irrespective of plant water status. The larger variability in MDS than in midday stem water potential was probably related to the fact that MDS is a measure of length and not of water potential. Thus, the variability of MDS could be attributed to differences in size of the shrinking tissue and to differences in the conductance of water between the bark and the xylem vessels; these sources of variability are independent of plant water status.

The present data suggest that determination of the water status of a particular orchard would require more measurements of MDS than of midday stem water potential (Fig. 1A-B). Furthermore, setting a threshold for irrigation scheduling on the basis of MDS measurements is likely to be more complicated, because thresholds might change from one commercial plot to another due to changes in parameters that affect the thickness of the trunk bark, such as tree age and rootstock.

Our data show that the choice of a particular water stress indicator is related to a few parameters where sensitivity to changes in moisture availability around the threshold for irrigation would be a predominant factor. Nevertheless, variability should not be ignored, as the combination of the sensitivity and variability would determine how many measurements would be needed to determine properly the plant water status in a certain orchard.
Literature Cited

Aston. A.R., and C.H.M. van Bavel. 1972. Soil surface water depletion and leaf temperature. Agron. J. 64:368-373.

Chone, X., C. van Leeuwen, D. Dubourdieu, and J.P. Gaudillere. 2001. Stem water potential is a sensitive indicator of grapevine water status. Ann. Bot. 87:477-483.

Cohen, M., D. Goldhamer, E. Fereres, J. Girona, and M. Mata. 2001. Assesment of peach tree responses to irrigation water deficits with continuous monitoring of trunk diameter fluctuations. J. Hort. Sci. Biotechnol. 76:55-60.

Cohen, Y., M. Fuchs, and G.C. Green. 1981. Improvement of the heat pulse method for determining sap flow in trees. Plant Cell Environ. 4:391-397.

Dixon, M.A. and M.T. Tyree. 1984. A new stem hygrometer, corrected for temperature gradients and calibrated against the pressure bomb. Plant Cell Environ. 7:693-697.

Fereres, E., D. Goldhamer, M. Cohen, J. Girona, and M. Mata. 1999. Continuous trunk diameter recording is a sensitive indicator for irrigation of peach trees. Calif. Agr. 53:July-August.

Fuchs, M. 1990. Infrared measurement of canopy temperature and detection of plant water stress. Theor. App. Clim. 42:253-261.

Goldhamer, D., E. Fereres, M. Mata, J. Girona, and M. Cohen. 1999a. Sensitivity of continuous and discrete plant and soil water status monitoring in peach trees subjected to deficit irrigation. J. Amer. Soc. Hort. Sci. 124:437-444.

Goldhamer, D.A., E. Fereres, M. Cohen, J. Girona, and M. Mata. 1999b. Comparison of continuous and discrete plant-based monitoring for detecting tree water deficits and barriers to grower adoption for irrigation management. Acta Hort. 537:431-445.

Gurunsinghe, S.H., and K.A. Shackel. 1995. The relation of cambial zone mechanical strength to growth and irrigation of almond [Prunus dulcis (Mills) Web] trees. J. Amer. Soc. Hort. Sci. 120:170-176.

Howell, T.A. 1996. Irrigation scheduling research and its impact on water use, p. 21-33. In: C.R. Camp, E.J. Sadler, and R.E. Yoder (eds.). Proc. Intl. Conf. Evapotranspiration and Irr. Scheduling, San Antonio, Texas, 3-6 Nov. 1996. Amer. Soc. Agr. Eng.

Huguet, J.G., S.H. Li, J.Y. Lorendeau, and G. Pellous. 1992. Specific micromorphometric reactions of fruit trees to water stress and irrigation scheduling automation. J. Hort. Sci. 67:631-640.

Itier, B. and Y. Brunet. 1996. Recent developments and present trends in evaporation research: A partial review, p. 1-20. In: C.R. Camp, E.J. Sadler, and R.E. Yoder (eds.). Proc. Intl. Conf. Evapotranspiration and Irr. Scheduling, San Antonio, Texas, 3-6 Nov. 1996. Amer. Soc. Agr. Eng.

Johnson, R.S., J. Ayers, T. Trout, R. Mead, and C. Phene. 2000. Crop coefficients for mature peach trees are well correlated with midday canopy light interception. Acta Hort. 537:455-460.

Jones, H.G., P.J.C. Hammer, and K.H. Higgs. 1988. Evaluation of various heat-pulse methods for estimation of sap flow in orchard trees: Comparison with micrometeorological estimates of evaporation. Trees 2:250-260.

Klepper, B. 1968. Diurnal pattern of water potential in woody plants. Plant Physiol. 43:1931-1934.

Klepper, B., V.D. Browning, and H.M. Taylor. 1971. Stem diameter in relation to plant water status. Plant Physiol. 48:683-685.

Lampinen, B.D., K.A. Shackel, S.M. Southwick, B. Olson, J.T. Yeager, and D. Goldhamer. 1995. Sensitivity of yield and fruit quality of French 
prune to water deprivation at different fruit growth stages. J. Amer. Soc. Hort. Sci. 120: 139-147.

Marsal, J., M. Mata, A. Arbones, J. Rufat, and J. Girona. 2002. Regulated deficit irrigation and rectification of irrigation scheduling in young pear trees: an evaluation based on vegetative and productive response. Europ. J. Agron. 17: 111-122.

McCutchan, H., and K.A. Shackel. 1992. Stem-water potential as a sensitive indicator of water stress in prune trees (Prunus domestica L. cv. French). J. Amer. Soc. Hort. Sci. 117:607-611.

Molz, F.J., and B. Klepper. 1973. On the mechanism of water-stress-induced stem deformation. Agron. J. 65:304-306.

Naor,A. 1999. Midday stem water potential as a plant water stress indicator for irrigation scheduling in fruit trees. Acta Hortic. 537:447-454.

Naor, A., I. Klein. and I. Doron. 1995. Stem water potential and apple fruit size. J. Amer. Soc. Hort. Sci. 120:577-582.

Naor, A., I. Klein, I. Doron, Y. Gal, Z. Ben-David, and B. Bravdo. 1997. The effect of irrigation and crop load on stem water potential and apple fruit size. J. Hort. Sci. 72:765-771.

Naor, A., I. Klein, H. Hupert, Y. Greenblat, M. Peres, and A. Kaufman. 1999. Water stress and crop level interactions in relation to nectarine yield, fruit size distribution and water potentials. J. Amer. Soc. Hort. Sci. 124:189-193.

Naor, A., M. Peres, Y. Greenblat, I. Doron, Y. Gal, and R.A. Stern. 2000. Irrigation and crop load interactions in relation to pear yield and fruit-size distribution. J. Hort. Sci. Biotechnol. 75:555-561.

Naor, A., H. Hupert, Y. Greenblat, M. Peres, and I. Klein. 2001. The response of nectarine fruit size and midday stem water potential to irrigation level in stage III and crop load. J. Amer. Soc. Hort. Sci. 126:140-143.

Phene, C.J., R.J. Reginato, B. Itier, and B.R. Tanner. 1990. Sensing irrigation needs, p. 207-261. In: G.J. Hoffman, T.A. Howel, and K.H. Solomon (eds.). Management of farm irrigation systems. Amer. Soc. Agr. Eng., St. Joseph, Mich.

Ramos, D.E., S.A. Weinbaum, K.A. Shackel, L.J. Schwankl, E.J. Mitcham, F.G.. Mitchell, R.G. Snyder, and G. McGourty. 1994. Influence of tree water status and canopy position on fruit size and quality of Bartlett pears. Acta Hort. 367:192-200.

Russo, D. and E. Bresler. 1982. Soil hydraulic properties as a stochastic process: II. Error of estimates in a heterogenous field. Soil. Sci. Soc. Amer. J. 46:20-26.

Russo. D., J. Zaidel, and A. Laufer. 1994. Stochastic analysis of solute transport in partially saturated heterogenous soil 1. Numerical experiments. Water Resour. Res. 30:769-779.

Scholander, P.F., H.T. Hammel, E.D. Bradstreet, and E.A. Hemmingsen. 1965. Sap pressure in vascular plants. Science 148:339-346.

Shackel, K.A., H. Ahmadi, W. Biasi, R. Buchner, D. Goldhamer, S. Gurusinghe, J. Hasey, D. Kester, B. Krueger, B.B. Lampinen, G. McGourty, W. Micke, E. Mitcham, B. Olsen, K. Pelletrau, H. Philips, D. Ramos, L. Scheankl, S. Sibbert, R. Snyder, S. Southwick, M. Stevenson, M. Thorpe, S. Weinbaum, and J. Yeager. 1997. Plant water status as an index of irrigation need in deciduous fruit trees. HortTechnology 7:23-29.

Shackel, K.A., B. Lampinen, S. Southwick, W. Olson, S. Sibbett, W. Kruger, J. Jager, and D. Goldhamer. 2000. Deficit irrigation: Maintaining productivity with less water. HortScience 35:1063-1066.

Stern R., M. Meron, A. Naor, S. Gazit, B. Bravdo, and R. Wallach, 1998. Effect of autumnal irrigation level in 'Mauritius' lychee on soil and plant water status and following year flowering intensity and yield. J. Amer. Soc. Hort. Sci. 123:150-155.

Warrick, A.W. and D.R. Nielsen 1980. Spatial variability of soil physical properties in the field, $\mathrm{p}$. 319-344. In: D. Hillel (ed.). Applications of soil physics. Academic Press, New York. 